\title{
Identification of a novel ERF gene, TaERF8, associated with plant height and yield in wheat
}

\author{
Lei Zhang ${ }^{1}$, Pan Liu², Jing Wu², Linyi Qiao', Guangyao Zhao², Jizeng Jia², Lifeng Gao ${ }^{2^{*}}$ and Jianming Wang ${ }^{1^{*}}$
}

\begin{abstract}
Background: Ethylene Responsive Factor (ERF) is involved in various processes of plant development and stress responses. In wheat, several ERFs have been identified and their roles in mediating biotic or abiotic stresses have been elucidated. However, their effects on wheat plant architecture and yield-related traits remain poorly studied.

Results: In this study, TaERF8, a new member of the ERF family, was isolated in wheat (Triticum aestivum L.). Three homoeologous TaERF8 genes, TaERF8-2A, TaERF8-2B and TaERF8-2D (named according to sub-genomic origin), were cloned from the common wheat cultivar Chinese Spring. The three homoeologs showed highly similar protein sequences, with identical AP2 domain. Whereas homoeologs sequence polymorphism analysis allowed the establishment of ten, two and three haplotypes, respectively. Expression analysis revealed that TaERF8s were constitutively expressed through entire wheat developmental stages. Analysis of related agronomic traits of TaERF8$2 B$ overexpressing transgenic lines showed that TaERF8- $2 B$ plays a role in regulating plant architecture and yieldrelated traits. Association analysis between TaERF8-2B haplotypes (Hap-2B-1 and Hap-2B-2) and agronomic traits showed that TaERF8-2B was associated with plant height, heading date and 1000 kernel weight (TKW). The TaERF8$2 B$ haplotypes distribution analysis revealed that Hap-2B-2 frequency increased in domesticated emmer wheat and modern varieties, being predominant in five major China wheat producing zones.

Conclusion: These results indicated that TaERF8s are differentially involved in the regulation of wheat growth and development. Haplotype Hap-2B-2 was favored during domestication and in Chinese wheat breeding. Unveiling that the here described molecular marker TaERF8-2B-InDel could be used for marker-assisted selection, plant architecture and TKW improvement in wheat breeding.
\end{abstract}

Keywords: ERF transcription factor, TaERF8, Haplotypes, Wheat

\section{Background}

The APETALA2/Ethylene Responsive Factor (AP2/ERF) superfamily, one of the largest transcription factor families in the plant kingdom [1], is widely involved in various regulatory events, including plant development, plant defense as well as response to environmental stimuli [2]. The AP2/ERF superfamily is characterized by the

\footnotetext{
*Correspondence: jm.w@163.com; gaolifeng@caas.cn

${ }^{1}$ College of Agronomy, Shanxi Agricultural University, Taigu, China ${ }^{2}$ Institute of Crop Sciences, Chinese Academy of Agricultural Sciences, Beijing, China
}

AP2 domain, which was first identified in regulator proteins for Arabidopsis flower development. Based on the number of AP2 domains and other structural features, the AP2/ERF superfamily is divided into four families: ERF, AP2, RAV, and the soloist [3, 4]. Among them, the ERF family can be further divided into two subfamilies: ERF and DREB [2]. The ERF subfamily is characterized by two characteristic conserved amino acid residues in the $\beta$-sheet of the AP2 domain, namely the 14th Ala (A14) and the 19th Asp (D19), which distinguish the ERF subfamily from the DREB subfamily [5].

(c) The Author(s). 2020 Open Access This article is licensed under a Creative Commons Attribution 4.0 International License, which permits use, sharing, adaptation, distribution and reproduction in any medium or format, as long as you give appropriate credit to the original author(s) and the source, provide a link to the Creative Commons licence, and indicate if changes were made. The images or other third party material in this article are included in the article's Creative Commons licence, unless indicated otherwise in a credit line to the material. If material is not included in the article's Creative Commons licence and your intended use is not permitted by statutory regulation or exceeds the permitted use, you will need to obtain permission directly from the copyright holder. To view a copy of this licence, visit http://creativecommons.org/licenses/by/4.0/ The Creative Commons Public Domain Dedication waiver (http://creativecommons.org/publicdomain/zero/1.0/) applies to the data made available in this article, unless otherwise stated in a credit line to the data. 
Transcription factors of the ERF subfamily participate in a variety of regulatory events. To date, a large number of ERF genes have been shown to enhance tolerance to abiotic stress or resistance to multiple diseases when over-expressed in transgenic plants, making them ideal candidates for crop improvement [6]. The ectopic expression of the tomato ERF genes JERF1 and JERF3 in rice improves tolerance to drought $[7,8]$. Overexpression of tomato OPBP1 confers resistance to fungal and bacterial pathogens of transgenic tobacco plants [9]. Likewise, tobacco NtERF5 overexpression enhances resistance to tobacco mosaic virus [10]. In addition, constitutive expression of rice ERF gene Sub1A enhances submergence tolerance [11], while other rice ERF genes such as SNORKEL1 and SNORKEL2 improve the adaptability of transgenic plants to deep water [12]. So far, several wheat ERF genes have been reported to be involved in stress responses. Over-expression of TaERF1 and TaERF3 enhance drought tolerance, while TaPIE1 improves freezing stress tolerance of transgenic wheat plants $[6,13,14]$. Furthermore, wheat plants overexpressing TaPIE1 also show increased resistance to necrotrophic pathogen Rhizoctonia cerealis [14]. Apart from responding to abiotic or biotic stresses, their roles in regulating growth and developmental processes have also been elaborated in previous studies [2, 6]. ERF BUD ENHANCER (EBE), an ERF gene in Arabidopsis, has been reported to affect shoot branching and axillary bud outgrowth [15]. In rice, the MULTI-FLORET SPIKELET1 (MFS1) gene is reported to regulate spikelet meristem determinacy and floral organ identity [16]. OsEATB, another rice ERF gene, restricts internode elongation, resulting in reduced plant height and panicle length [17]. Overexpression of AP37 increases grain filling rate as well as grain yield in rice [18]. In barley, com 2 participates in spike branching, which alters inflorescence architecture, resulting in more grain per spike and higher yield [19]. To date, only a few ERFs have been characterized from wheat, and researches have mainly focused on their roles in defending against pathogen attack or abiotic stress responses [20-22]. In addition, only two studies have shown that ERF genes such as WFZP of hexaploid wheat and branched head ${ }^{t}\left(b h^{t}\right)$ of tetraploid wheat play important roles in regulating plant development $[23,24]$. Therefore, it was advisable to identify and characterize novel ERF genes involved in wheat development, for genetic enrichment and enhancement of genetic-driven wheat breeding.

Here, we isolated and characterized a novel ERF member, TaERF8, in wheat (Triticum aestivum L.). Our findings suggest that TaERF8 is involved in wheat growth and development, including regulation agronomic traits such as plant height, heading date, kernel width and TKW. In this study, the genomic sequences of TaERF8s in different wheat accessions were analyzed, being identified several haplotypes for each of the homoeologous genes. Molecular marker TaERF8-2B-InDel was developed for marker-assisted selection in wheat breeding and for wheat population studies. Haplotype Hap- $2 B-2$ was unveiled as selected during Chinese wheat breeding. Association analysis showed that TaERF8-2B plays a role in plant architecture and yield-related traits.

\section{Results}

\section{Cloning and characterization of TaERF8s}

TaERF8 was screened from the sequence library of a project on the introduction of large-scale wheat transcription factor genes into rice [25]. General primer P-G was used to obtain both the coding and genomic sequences of TaERF8, allowing the isolation of three TaERF8 homoeologous genes from the common wheat cultivar Chinese Spring. Isolated homoeologs were designated as TaERF8-2A, TaERF8-2B and TaERF8-2D according to their genomic origins (Additional file 1: Figure S1). The TaERF8 homoeologs encoded highly homologous proteins ( $>96 \%$ identity) with lengths of 251, 253 and 253 amino acids, respectively. All three homoeologs shared the same sequence within the AP2 domain, implying that they may have similar functions in wheat, including the ERF subfamily characteristics A14 and D19 in their AP2 domain (Fig. 1a). These similarities allowed their classification as ERF subfamily members, being further grouped into the B4 family according to Sakuma [26]. TaERF8s and ERFs orthologs from Arabidopsis thaliana and Oryza sativa were grouped into the same clade in the inferred neighbor-joining phylogenetic tree (Fig. 1b), suggesting that TaERF8s might possess similar functions compared to these ERFs.

\section{Sequence polymorphism and molecular markers development}

Gene-specific primers P-gA, P-gB and P-gD (see Methods section) were employed to amplify the genomic and flanking sequences of TaERF8-2A, TaERF8-2B and TaERF8-2D, respectively, in different wheat accessions (Additional file 2: Table S1) to detect sequence polymorphisms in the three genomes. For TaERF8-2A, a total of 24 single nucleotide polymorphism (SNPs) sites were detected, forming 10 haplotypes, Hap-2A-1 10 (Fig. 2a). Of the 24. SNPs, six were found within exons, nine in the intron, and the rest were found at the promoter region. Molecular marker TaERF8-2A-SNP was developed on the SNP detected at 274 bp (T/C) for mapping TaERF8-2A to Yanzhan1 (YZ1)/Neixiang188 (NX188) [28] genetic map (Fig. $2 \mathrm{~b}$ and c). For TaERF8-2B, no SNPs were detected in the coding region, whereas three SNPs (at -99 bp, $1335 \mathrm{bp}$, and $1478 \mathrm{bp}$ ) and a 3-bp InDel (from $-455 \mathrm{bp}$ to $-453 \mathrm{bp}$ ) were identified in upstream and downstream regions. With those four polymorphisms, two haplotypes were established, namely Hap- 


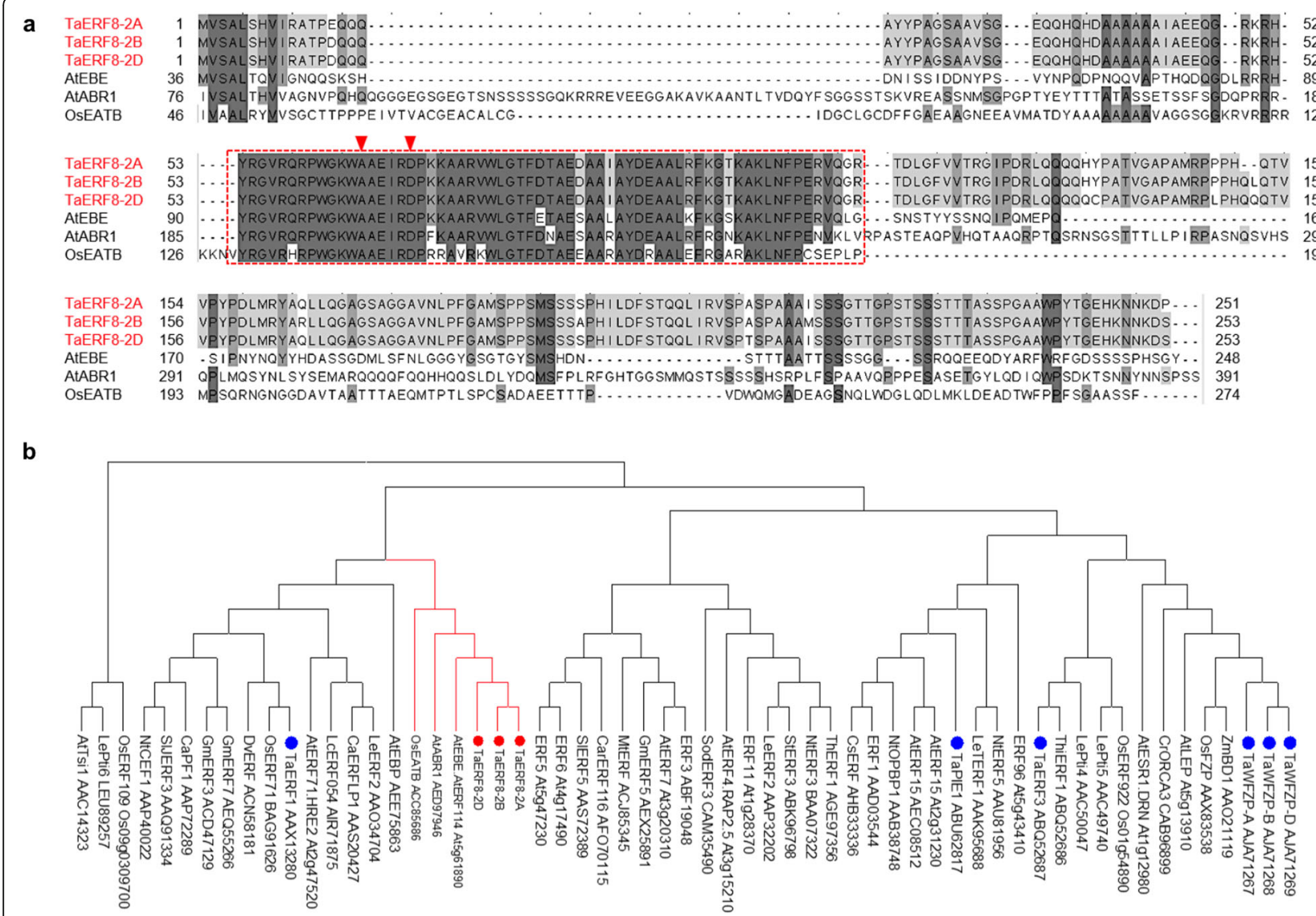

Fig. 1 Wheat TaERF8s belong to the ERF family. a Alignment of ERFs from different plant species; The conserved AP2 domains were marked in red rectangle; typical amino acid residues at the14th $(\mathbf{a})$ and the 19th $(\mathbf{d})$ positions of $\beta$-sheet were indicated by red triangle. $\mathbf{b}$ Phylogenetic tree of ERF proteins. TaERF8-2A, TaERF8-2B and TaERF8-2D were marked with red dots; blue dots indicated some of the ERFs identified in wheat

$2 B-1$ and Hap-2B-2 (Fig. 2d). Molecular marker TaERF8$2 B$-InDel was developed on the 3-bp InDel site to distinguish the two haplotypes (Fig. 2e and f). And finally, in TaERF8-2D, two SNPs at 830 bp and 949 bp were found, identifying three haplotypes, Hap-2D-1, Hap-2D-2 and Hap-2D-3 (Fig. 2g) (Additional file 3: Figure S2).

\section{Chromosomal locations of TaERF8s}

The chromosomal locations of the three TaERF8 homoeologous genes were verified using the Chinese Spring nullisomictetrasomic lines and wheat accessions including diploid, tetraploid and hexaploid wheat (Additional file 2: Table S1). The PCR results showed that gene-specific primers for TaERF8-2A, TaERF8-2B and TaERF8-2D were amplified only in the presence of chromosomes $2 \mathrm{~A}, 2 \mathrm{~B}$ and $2 \mathrm{D}$, respectively (Fig. 3a). The TaERF8-2A gene was mapped to a genetic region flanked by Xwpt2882 ( $8.5 \mathrm{cM})$ and Xwpt3114 $(2.7 \mathrm{cM})$ by scanning the recombinant inbred line (RIL) population of 199 lines developed by YZ1/NX188 crossing [28] using marker TaERF8-2A-SNP (Fig. 3b). TaERF8-2B was mapped to a region flanked by Xwmc223 $(3.8 \mathrm{cM})$ and Xgwm388 $(5.7 \mathrm{cM})$ by scanning the doubled haploid (DH) population derived from
Hanxuan10 (H10)/Lumai14 (L14) crossing using marker TaERF8-2B-InDel (Fig. 3c).

\section{Expression patterns of TaERF8s in wheat}

The expression analysis was performed using common wheat Chinese Spring plants. Gene-specific primers P-qA, $\mathrm{P}-\mathrm{qB}$ and $\mathrm{P}-\mathrm{qD}$ were used to detect the expression patterns of TaERF8s in various tissues at different developmental stages by quantitative real-time PCR (qRT-PCR). As shown in Fig. 4, transcripts of TaERF8-2A, $2 B$ and $2 D$ were identified in all the tested tissues, with higher levels of expression in leaf at the seedling stages and in root at the jointing stage. The expression level in tissues like internodes and spike was much lower. The constitutive expression patterns indicated that TaERF8s might play active roles through the entire growth cycle of wheat.

\section{Association of TaERF8-2B haplotypes with agronomic traits}

The association analysis between TaERF8- $2 B$ haplotypes and agronomic traits was based on accessions summarized in sample set 1 (Additional file 4: Table 

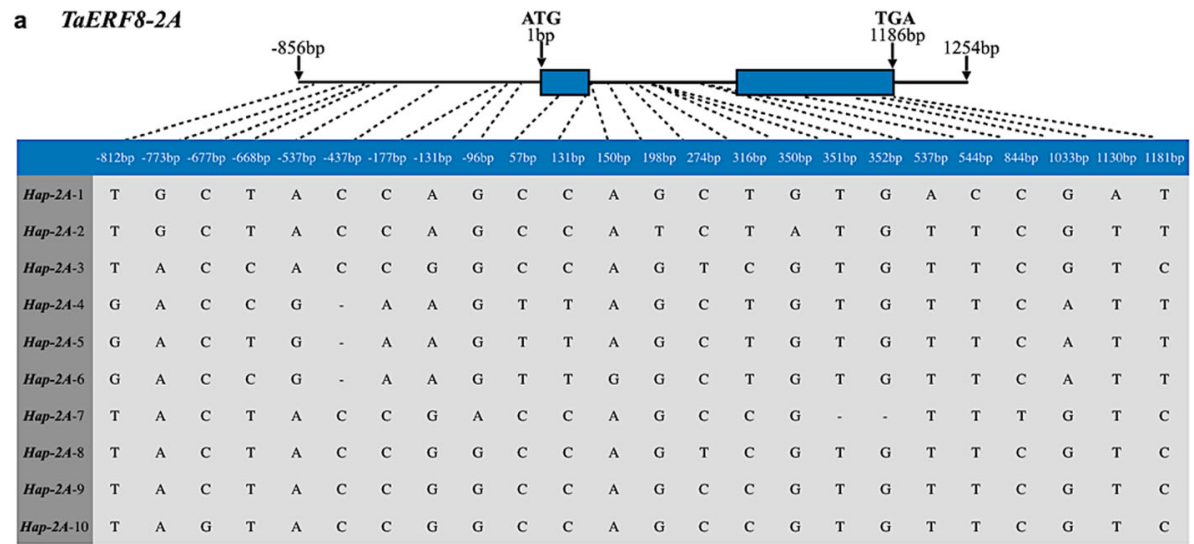

b

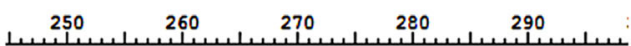
CTAGATGAATCGCAGCCATITGgaAACtTYGAATCATCCAAACACGTCGATATA CTAGATGAATCGCAGCCATTTGGAAACTTI GAATCATCCAAACACGTCGATATA CTAGATGAATCGCAGCCATITGGAAACITCGAATCATCCAAACACGTCGATATA

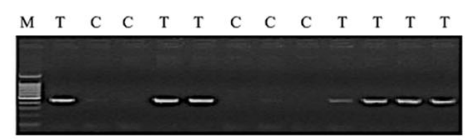

d TaERF8-2B

e

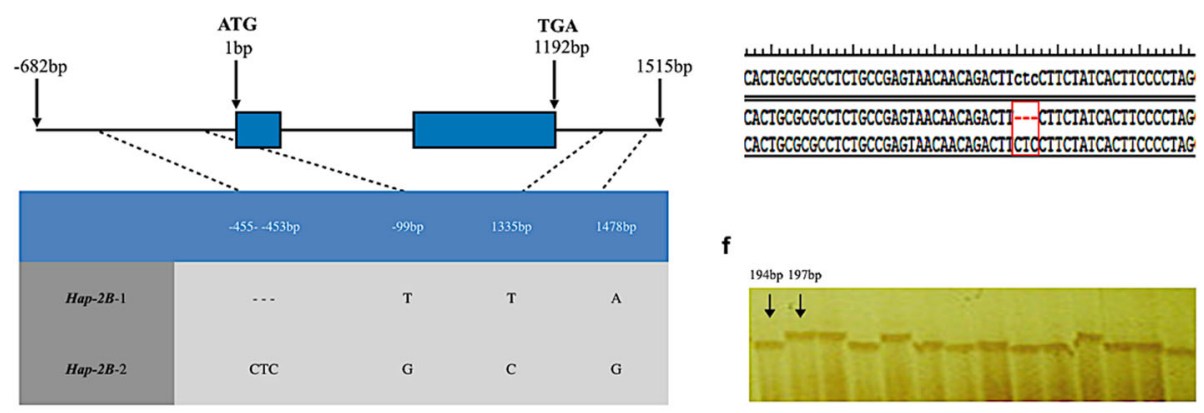

g TaERF8-2D

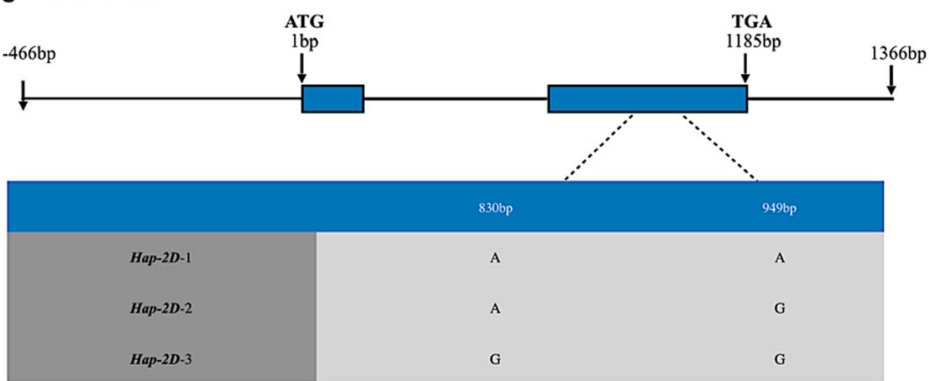

Fig. 2 Sequence polymorphism and molecular marker of TaERF8S. a SNPs found in TaERF8-2A among different wheat accessions. b Molecular marker TaERF8-2A-SNP was developed based on the SNP detected at $274 \mathrm{bp}$ (T/C). c PCR products were obtained by screening the YZ1/NX188 population using marker TaERF8-2A-SNP. M: Marker III. d SNPs and InDel found in TaERF8-2B among different wheat accessions. e Molecular marker TaERF8-2B-InDel was developed based on the polymorphic InDel (---/CTC) site. f Products were obtained by screening the H10/L14 population [27] using marker TaERF8-2B-InDel. g SNPs found in TaERF8-2D among different wheat accessions

S2). Phenotypic data was collected from Beijing (BJ), Luoyang (LY), Xinxiang (XX) and Jiaozuo (JZ), respectively, during the growing seasons of 2012, 2014 and 2015. Significant associations were found between TaERF8-2B haplotypes and agronomic traits such as plant height, heading date and TKW (Additional file 5: Table S3). In addition, significant differences were observed for the two haplotypes of TaERF8-2B (Additional file 6: Table S4). Accessions possessed Hap$2 B-2$ exhibited shorter plant height $(16.5 \mathrm{~cm}-25.7 \mathrm{~cm})$, earlier heading date (1.4d-3.0d) and higher TKW (5.1 g-8.0 g) than those possessed Hap-2B-1 (Fig. 5). These results implied that TaERF8- $2 B$ might be involved in multiple processes of wheat growth and development. 


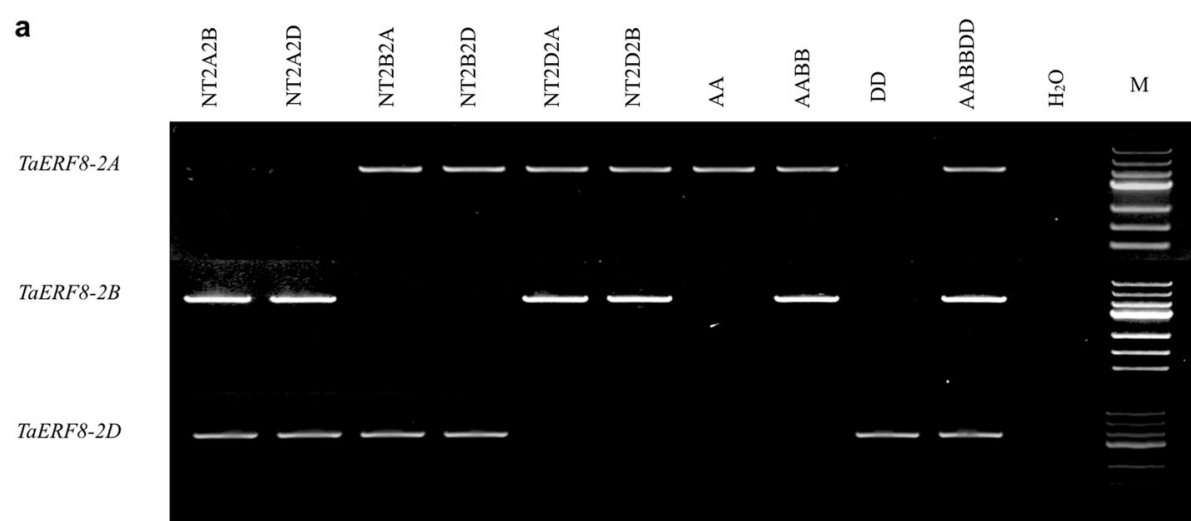

b

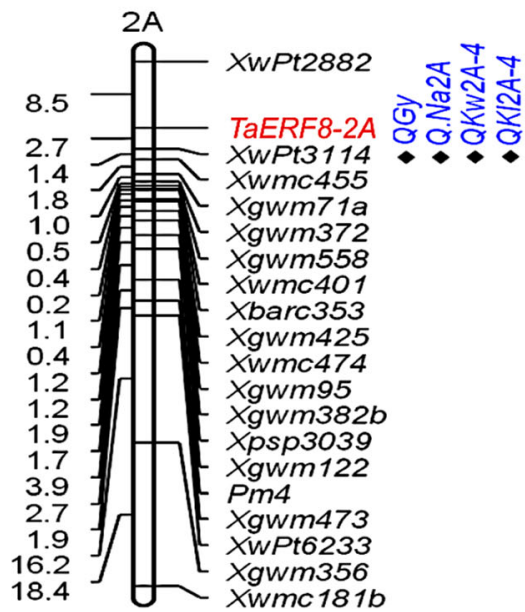

c

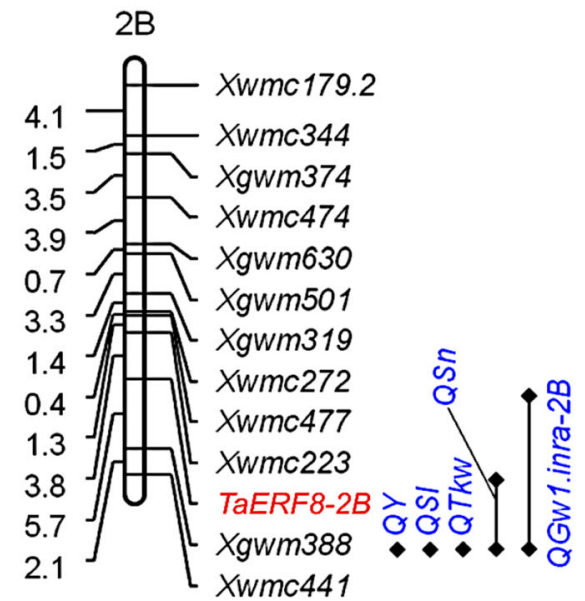

Fig. 3 Chromosomal localization of TaERF8s. a Localization of TaERF8s on homoeologous group 2 using Chinese Spring nullisomic-tetrasomic lines, diploid, tetraploid and hexaploid wheat. AA: T.urartu; AABB: T.dicoccoides; DD: A.tauschii; AABBDD: Chinese Spring; M: DNA Marker III. b TaERF8-2A was mapped to chromosome 2A flanked by Xwpt2882 and Xwpt3114. c TaERF8-2B was mapped to chromosome 2B flanked by XWm 223 and Xgwm388. Locations of TaERF8-2A and TaERF8-2B were marked in red, black diamonds indicate QTL associated with agronomic traits reported previously, QGy [27]; QNa2A [27, 29]; QKW2A-4 and QKI2A-4 [30]; QY [31]; QSI and QTkw [32]; QSn [33]; QGw1.inra-2B [34]

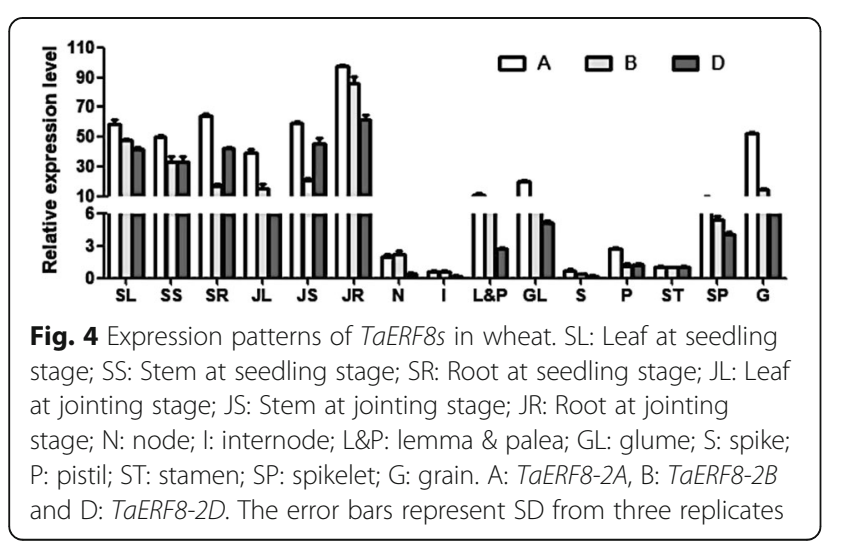

TaERF8-2B underwent selection in Chinese wheat breeding

To determine whether TaERF8-2B had undergone selection pressure, we investigated the frequency and distribution of the two haplotypes based on sample set 1 and 2 (Additional file 7: Table S5). The results showed that the haplotype diversity of TaERF8- $2 B$ decreased in domesticated emmer wheat and modern varieties, suggesting that TaERF8-2B was selected during the domestication and Chinese wheat breeding. The proportion of Hap-2B-1 decreased from $15 \%$ of wild emmer wheat to $6 \%$ of domesticated emmer wheat, and the proportion decreased significantly from $29.2 \%$ of wheat landraces to $6.8 \%$ of modern varieties (Fig. 6a). On the contrary, the proportion of Hap-2B-2 increased in both domesticated emmer wheat and modern varieties, indicating that Hap-2B-2 experienced a positive selection and was the favored haplotype. We further investigated the geographic distribution of TaERF8- $2 B$ haplotypes 


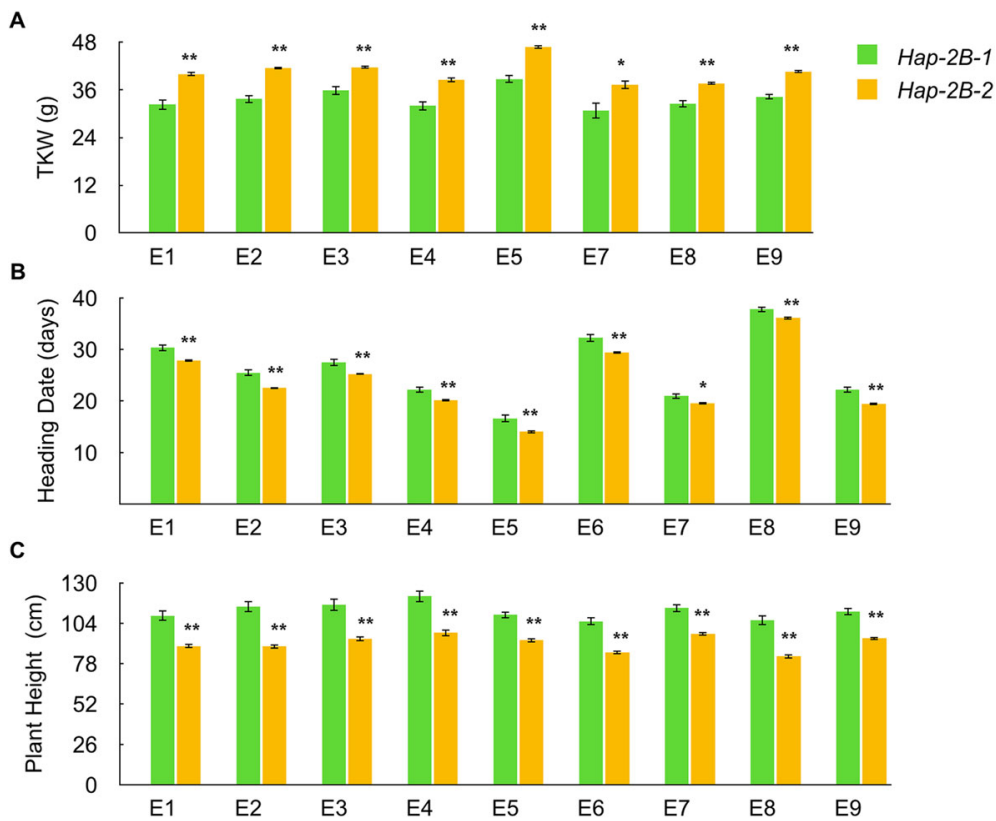

Fig. 5 Phenotypic comparisons of two TaERF8-2B haplotypes in nine environments. Traits were TKW (a), heading date (b) and plant height (c). E1 to E9 indicated the environments of 2012-BJ, 2012-XX, 2012-JZ, 2012-LY, 2014-XX, 2014-BJ, 2015-XX, 2015-BJ and 2015-JZ, respectively. Heading Date (days from April 1st). The error bars represent SE; ${ }^{*} P<0.05$, ** $P<0.01$

based on sample set 3 (Additional file 8: Table S6) from five major wheat-producing zones in China, including the Northeastern Spring Wheat Zone (I), the Northern Winter Wheat Zone (II), the Huanghuai River Winter Wheat Zone (III), the middle and lower reaches of Yangtze River Winter Wheat Zone (IV) and the Southwestern Winter Wheat Zone (V) (Fig. 6b). The results showed that in all five zones, the frequency of Hap- $2 B-2$ was higher than that of Hap-2B-1, indicating that Hap- $2 B-2$ was selected and the dominant haplotype in the five Zones. The frequency of Hap- $2 B-2$ was the highest in Zone V (93\%), followed by Zones IV, III, and II, and was the lowest in Zone I (63.6\%) where the latitude is high.
In addition, the frequency of Hap-2B-2 in five wheatproducing zones increased in a stepwise manner from north to south, while the frequency of Hap-2B-1 displayed the opposite trend.

\section{Overexpression of TaERF8-2B in wheat influences overall plant development}

To characterize the functions of TaERF8- $2 B$, the coding sequence of TaERF8-2B was transformed into the common wheat cultivar Kenong199. Four independent TaERF8-2Boverexpression transgenic lines were obtained, and two transgenic lines with different expression levels were used for phenotypic identification (Additional file 9: Figure S3).
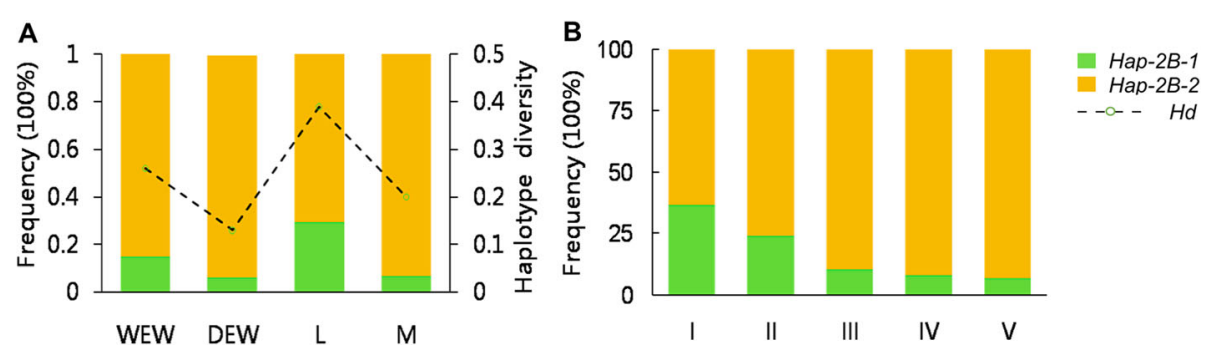

Fig. 6 Favored haplotype was selected during domestication and Chinese wheat breeding. a Frequency of TaERF8-2B haplotypes in sample set 1 and 2. WEW: wild emmer wheat; DEW: domesticated emmer wheat; L: landraces; M: modern varieties; Hd: haplotype diversity. b Geographic distribution of TaERF8-2B haplotypes in five major wheat-producing zones in China. Zone I: the Northeastern Spring Wheat Zone; II: the Northern Winter Wheat Zone; III: the Huanghuai River Winter Wheat Zone; IV: the middle and lower reaches of Yangtze River Winter Wheat Zone; IV: the Southwestern Winter Wheat Zone 
Several agronomic traits including plant height, heading date, kernel width and TKW were investigated between the TaERF8-2B transgenic lines and wild type. The results showed that the TaERF8- $2 B$ transgenic lines exhibited significantly reduced plant height, earlier heading date, increased TKW and wider kernel width compared to the wild type (Fig. 7). The TaERF8-2B transgenic lines exhibited significant changes in the architecture and development of wheat, indicating TaERF8-2B might have multiple effects in modulating wheat growth.

\section{Discussion}

\section{TaERF8 is a novel member of the wheat ERF family}

Members of ERF family, which belongs to the AP2/ERF superfamily, are involved in regulation of various processes of plant development and stress responses [5]. To date, a variety of wheat ERFs have been identified and characterized in previous studies [20-24], focusing primarily on their roles in biotic and abiotic stress responses, but little attention has been paid to their roles in relation to yield-related traits. Here, we reported three TaERF8s, as members of wheat ERF by sequence homology and protein similarity, and focused on functions related to plant architecture and growth. In this study, TaERF8-2A was mapped to a pericentromeric region of chromosome 2A (flanked by Xwpt2882 (8.5 cM) and Xwpt3114 (2.7 cM)), where quantitative trait loci (QTL) for several important agronomic traits were found in previous studies [27, 29, 30], including QGy for grain yield [27], $Q K w 2 A-4$ for kernel width and $Q K l 2 A-4$ for kernel length [30]. Besides, marker Xwpt3114 has been reported to be associated with flowering time and $\mathrm{Na}+$ exclusion [27, 29]. TaERF8-2B was also mapped to a pericentromeric region of chromosome 2B (flanked by $X w m c 223(3.8 \mathrm{cM})$ and $X g w m 388(5.7 \mathrm{cM}))$. In this region of chromosome $2 \mathrm{~B}$, several QTLs controlling yieldrelated traits, such as spike length [32], TKW [32, 34], number of fertile spikelets [33] and high yield [31] were detected. As indicated in the results sections, we found that TaERF8-2B was related to plant height, heading date and TKW, being the first time that a link between wheat ERF genes and agronomic traits has been established in this chromosomal interval.

Gene expression studies showed that TaERF8s were constitutively expressed in multiple tissues at different developmental stages, suggesting their roles as pleiotropic genes in multiple developmental processes. It has been reported that overexpression of the rice ERF gene OsEATB results in reduced plant height, and panicle length while increased number of tillers and spikelets [17]. Another Arabidopsis ERF gene, EBE, has impact on shoot branching, and the overexpression plants stimulate axillary bud formation and outgrowth [15]. The three TaERF8s here reported were clustered into the same clade as OsEATB and EBE. The overexpression of TaERF8-2B in wheat caused a range of changes, including reduced plant height, earlier heading date, wider kernel width and increased TKW per plant. Together, these data show that TaERF8 is a novel, pleiotropic gene in the wheat ERF gene family, involved in the regulation of wheat growth and development.

\section{TaERF8-2B is a regulatory factor in wheat growth and development}

Wheat is one of the most important food crops in the world, and the constant pursuit of increased yield
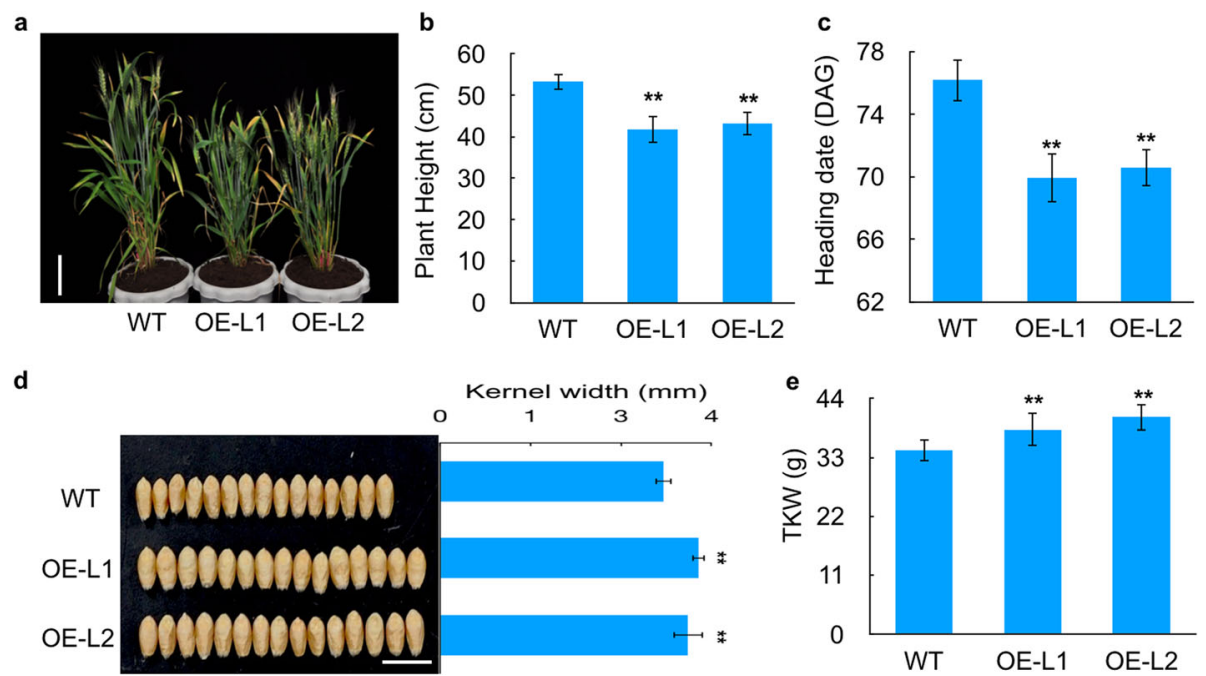

Fig. 7 Phenotypic analysis of TaERF8-2B-overexpression (OE) transgenic wheat. a Plant morphology of WT and two independent OE transgenic lines, scale bar:10 cm; comparison of OE transgenic lines and WT in plant height $\mathbf{b}$; heading date (c); kernel width, scale bar:10 mm (d); TKW (e). WT: wild type; data were means \pm SD of 20 plants; ${ }^{* *} P<0.01$ 
potential has become a major goal of breeding in China in recent decades [35]. As one of the three determinants of grain yield, TKW is believed to have a great impact on yield and is largely determined by kernel size, and in traits associated with kernel size, the kernel width displays the highest association with kernel weight [36-38]. In this study, association analysis and transgenic plants with higher TKW both confirmed that TaERF8-2B affects TKW, and the increased TKW in transgenic plants might be due to wider kernel width compared to the wild type.

Plant height is not only a decisive factor in plant architecture but also an important agronomic trait directly linked to yield potential [39]. Genes involved in GA signaling and biosynthesis have been used in breeding to modify and produce crops with reduced height, increased yield production and other beneficial traits [40-45], which can be best exemplified in the Green Revolution [46]. Previous studies have shown that some ERFs are related to GA in regulating plant height $[11,12,17]$. The rice ERF gene $O S E A T B$ restricts the internode elongation by downregulating a gibberellin biosynthetic gene, which results in reduced plant height and panicle length, and increased tiller and spikelet number in OsEATB-overexpressed plants [17]. Sub1A, another rice ERF gene, restricts the response to GA through elevating the expression of SLR1 and SLRL1 [11], while SK1 and SK2, also encode ERFs, trigger internode elongation via GA in response to flooding [12]. Here by sequence analysis, we identified a gibberellin-responsive element (GARE-motif) in the promoter region of TaERF8-2B. However, whether TaERF8$2 B$ is involved in GA-related plant height regulation still needs further investigation. Taken together, overexpressing TaERF8-2B led to a reduced height and changes in yield-related agronomic traits, suggesting its role in regulating plant architecture and growth.

\section{TaERF8-2B has undergone selection during wheat breeding}

Domesticated crops, including wheat, have undergone strong human selection aimed at developing cultivars with favorable traits to adapt to a wider range of environmental conditions [47]. Hexaploid bread wheat has experienced two major selection events, one is the selection from wild emmer wheat to domesticated emmer wheat during the domestication process, and the other is the selection that involves crop improvement from landraces to modern varieties during wheat breeding process [48]. In this study, we identified that TaERF8-2B had undergone the two selective events. The proportion of Hap-2B-1 decreased from $15 \%$ of wild emmer wheat to $6 \%$ of domesticated emmer wheat, and the proportion decreased significantly from $29.2 \%$ of wheat landraces to $6.8 \%$ of modern varieties. On the contrary, the proportion of Hap-2B-2 increased in both domesticated emmer wheat and modern varieties. The geographic distribution of TaERF8-2B haplotypes showed that the frequency of Hap- $2 B-2$ was higher than that of $H a p-2 B-1$ in five major wheat-producing zones of China, indicating that Hap-2B-2 was selected. Association analysis of TaERF8- $2 B$ haplotypes with agronomic traits showed that Hap-2B-2 was significantly associated with reduced plant height and higher TKW, which were favorable traits for wheat breeding. All of these results together indicated that Hap- $2 B-2$ had undergone positive selection, being the favored haplotype during Chinese wheat breeding. In addition, we noted a regional adaptation selection of Hap-2B-2. From northern to southern China, the frequency of Hap-2B-2 increased by more than $10 \%$, while the frequency of Hap- $2 B-1$ displayed the opposite trend. In general, varieties planted in the North regions of China possess enhanced photoperiod sensitivity, while varieties grown in southern China with lower latitude often exhibit reduced photoperiod sensitivity [49]. In this study, earlier heading date was observed for wheat overexpressing TaERF8-2B under long-day conditions, indicating that TaERF8- $2 B$ may affect the heading date. However, whether TaERF8-2B is involved in relevant pathways that modulate photoperiod sensitivity requires a more comprehensive analysis.

Given the large and complex genomes of wheat, knowledge about the function of specific gene associated with agronomic traits is important for the efficient selection of new haplotypes in breeding [50]. Functional markers, an ideal tool for marker-assisted breeding, have been developed for abiotic stress tolerance and agronomic traits including plant height and grain weight [51-53]. In this study, functional analysis of TaERF8- $2 B$ revealed its role in affecting plant height and yield-related traits, and the functional marker TaERF8-2B-InDel was successfully developed, being able to identify a selected haplotype (Hap-2B-2). Therefore, utilization of this functional marker could contribute to further improvement of plant architecture and TKW in wheat.

\section{Conclusions}

Three homoeologous genes of TaERF8, TaERF8-2A, TaERF8-2B and TaERF8-2D were cloned from the common wheat cultivar Chinese Spring. Sequence analysis showed that the three homoeologs were highly similar, possessing the same AP2 domain, and belonging to the ERF subfamily. Expression analysis revealed that TaERF8s were constitutively expressed through entire wheat developmental stages. Polymorphic sites were detected in TaERF8-2B, which allowed the development of breeding-assistant markers and the identification of haplotype selection in Chinese wheat breeding (Hap-2B2). Association analysis revealed that TaERF8-2B was significantly associated with plant height, heading date and TKW. In summary, the newly developed molecular 
marker TaERF8-2B-InDel may be useful for markerassisted selection, plant architecture and TKW improvement in wheat breeding.

\section{Methods}

Plant materials and growth conditions

Common wheat cultivar Chinese Spring was used to clone the TaERF8-2A, TaERF8-2B and TaERF8-2D genes. A total of 42 different wheat accessions including diploid, tetraploid and hexaploid wheat were used for polymorphism analysis of TaERF8s (Additional file 2: Table S1). The 42 accessions were planted in the experimental field of the Institute of Crop Science, the Chinese Academy of Agricultural Sciences, Beijing $\left(39^{\circ} \mathrm{N}, 116^{\circ} \mathrm{E}\right)$ in a 2-row $2 \mathrm{~m}$ plot with $50 \mathrm{~cm}$ between rows.

Association analysis of TaERF8-2B haplotypes with agronomic traits was performed using sample set 1 , which contains 367 wheat accessions, including 89 landraces and 278 modern varieties (Additional file 4: Table S2). The sample set 1 was planted in the growing seasons of 2012, 2014 and 2015 at four locations, viz., BJ $\left(40^{\circ} \mathrm{N}, 116^{\circ} \mathrm{E}\right), \mathrm{XX}$ $\left(35^{\circ} \mathrm{N}, 113^{\circ} \mathrm{E}\right), \mathrm{LY}\left(33^{\circ} \mathrm{N}, 111^{\circ} \mathrm{E}\right)$ and $\mathrm{JZ}\left(35^{\circ} \mathrm{N}, 113^{\circ} \mathrm{E}\right)$ in a 4-row $2 \mathrm{~m}$ plot with $25 \mathrm{~cm}$ between rows. Field managements, including irrigation, fertilization and pest control were carried out according to local production conditions. Phenotypic assessment of plant height, heading date and TKW was performed under 9 environments (E1 to E9) (Additional file 6: Table S4). E1 to E9 indicated the environments at BJ, XX, JZ and LY in 2012, XX, BJ in 2014 and XX, BJ and JZ in 2015, respectively. For each accession, plant height was averaged by measuring 8 individual plants, heading date was recorded when $50 \%$ plants showed fully emerged spikes, and TKW was calculated by 5 times of the weight of 200 grains.

Frequency of TaERF8-2B haplotypes was calculated based on sample set 1 and 2 . The sample set 2 consisted of 107 wild and 32 domesticated tetraploid wheat (Additional file 7 : Table S5). Sample set 3 (Additional file 8: Table S6) was used to illustrate the geographic distribution of TaERF8-2B haplotypes in different wheat production zones in China. These accessions were planted in 2015 growing season at XX $\left(35^{\circ} \mathrm{N}, 113^{\circ} \mathrm{E}\right)$, and field managements were conducted according to local production conditions. Accessions of sample set 2 were planted as single $50 \mathrm{~cm} \times 2 \mathrm{~m}$ plots and sample set 3 were in a 2 -row $25 \mathrm{~cm} \times 2 \mathrm{~m}$ plots.

The RIL population of 199 lines developed by YZ1/ NX188 crossing [28], and DH population derived from H10/L14 crossing [54] were used for linkage mapping. The RIL population was grown at Luoyang $\left(33^{\circ} \mathrm{N}, 111^{\circ} \mathrm{E}\right)$ in 2015 growing season. Thirty seeds of each line were sown in a 2-row plot of $2 \mathrm{~m}$ in length. The pUbi: TaERF8-2B transgenic lines used in this study were in the wheat cultivar Kenong199 background. Kenong199 and transgenic plants were cultured in plastic pots filled with Pindstrup substrate (Pindstrup, Denmark), a peatbased potting mix, and placed in a controlled growth chamber under the $16 \mathrm{~h}$ light $/ 8 \mathrm{~h}$ dark photoperiod at $22^{\circ} \mathrm{C}$. Watering was repeated every two or three days. The DH population derived from H10/L14 crossing was kindly provided by Dr. Ruilian Jing of the Institute of Crop Science, Chinese Academy of Agricultural Sciences, and the other plant materials used in this study were provided by the Key Laboratory of Crop Gene Resources and Germplasm Enhancement of the Institute of Crop Science, Chinese Academy of Agricultural Sciences.

\section{Data analysis}

In association analysis, 367 accessions were classified into group 1 and group 2 according to the two haplotypes of TaERF8-2B, respectively. Genotypic and phenotypic data were imported and analyzed using SPSS 19.0 software (SPSS Inc., USA). Correlation between TaERF8-2B haplotypes and agronomic traits was analyzed, the mean comparison of agronomic traits between the two haplotypes was performed, and the statistical t-test was applied to confirm the significance. Association was considered significant at $P<0.05$. Frequency of TaERF8-2B haplotypes was calculated based on sample set 1 and 2 . Haplotype diversity of TaERF8- $2 B$ was calculated for sample set 2 using Powermarker software [55].

\section{Cloning and chromosomal locations of the three TaERF8 genes}

In this study, the general primer pair P-G (5'-CCGTAT CACCACCTCATC-3' and 5'-TGCGTATTCCTCAT CTACTG-3') was used to amplify the genomic and fulllength cDNA sequences of TaERF8 from Chinese Spring. PCR amplification was performed in $25 \mu \mathrm{L}$ volume including $1 \mu \mathrm{L} 100 \mathrm{ng} / \mu \mathrm{L}$ cDNA or genomic DNA, $7.5 \mathrm{pmol}$ of each primer, $5 \mu \mathrm{L} 2 \mathrm{mM}$ dNTPs, $12.5 \mu \mathrm{L} 2 \times$ PCR buffer for KOD FX Neo, and $0.5 \mu \mathrm{L}(1.0 \mathrm{U} / \mu \mathrm{L})$ KOD FX Neo DNA Polymerase (Toyobo, Japan). The amplification procedure was as follows: initial denaturation at $94{ }^{\circ} \mathrm{C}$ for $2 \mathrm{~min}$, followed by 33 cycles of denaturation at $98^{\circ} \mathrm{C}$ for $10 \mathrm{~s}$, annealing at $58^{\circ} \mathrm{C}$ for $30 \mathrm{~s}$, and extension at $68^{\circ} \mathrm{C}$ for $30 \mathrm{~s}-1 \mathrm{~min}$, with a final extension at $68^{\circ} \mathrm{C}$ for $10 \mathrm{~min}$. The amplified PCR product was cloned into pEASY-Blunt Zero cloning vectors (Transgen, China). Based on the sequence differences among the $\mathrm{A}, \mathrm{B}$ and $\mathrm{D}$ wheat genomes of TaERF8, three genespecific primers, P-gA (5'-CCAAATGTTGAGTG ACTTG-3' and 5' -TGCGTATTCCTCATCTACTG-3'), P-gB (5' -GAATGAACGGGAAATGTTATCCAT-3' and 5'-GAAACGATAAACGATTAGACCA-3') and P-gD (5'-CAGACTTCTCCTTCTATCACAT-3' and 5'-AAACAAAACAAGAGATTTAGATGA-3'), were designed. The amplification procedure was as follows: denaturation at $94{ }^{\circ} \mathrm{C}$ for $2 \mathrm{~min}$, followed by 33 cycles of 
denaturation at $98^{\circ} \mathrm{C}$ for $10 \mathrm{~s}$, annealing at $60^{\circ} \mathrm{C}$ for 30 $\mathrm{s}$, and extension at $68^{\circ} \mathrm{C}$ for $80 \mathrm{~s}$, with a final extension at $68^{\circ} \mathrm{C}$ for $10 \mathrm{~min}$. The gene-specific primers, Chinese Spring nullisomic-tetrasomic lines and wheat species of different ploidy (Additional file 2: Table S1) were then used to determine the chromosomal locations of the three homoeologous genes.

\section{Gene expression analysis of TaERF8}

Gene expression analysis of TaERF8 was performed using common wheat Chinese Spring plants. The Chinese Spring plants were splitted in leaf, stem, root, pistil, spikelet, node, internode, stamen, young spike, glume, lemma and palea at their precise developmental stage from at least six independent plants, mixed and fast frozen at $-80^{\circ} \mathrm{C}$ till RNA extraction. Total RNA extraction was performed with Direct-zol ${ }^{\text {Tix }}$ RNA miniprep kit (Zymo Research, USA) following manufacturer instructions. One microgram of total RNA of each sample was used for first-strand CDNA synthesis using the $5 \times$ All-In-One MasterMix kit (ABM, Canada). Specific primers for TaERF8-2A gene (P-qA: 5'-CCAGACCGTG GTGCCGTACC-3' and 5'-GCCGCCGCGGGAGACGCT3'), TaERF8-2B gene (P-qB: 5'-GACCTCATGCGGTA TGCACG-3' and 5' -TTGTGCCTGAGCTCGACATTG-3') and the TaERF8-2D gene (P-qD: $5^{\prime}$-CGACAGATTGCAGC AACAACAACAGTG-3' and 5'-CCCGTTGTGCCTGA GCTCGATATA- $3^{\prime}$ ) were used on this first-strand cDNA ( $2 \mu \mathrm{l}$ of ten times diluted first-strand cDNA) to determine relative transcript level for each wheat tissue by qRT-PCR. The qRT-PCR was performed using SYBR ${ }^{\circ}$ Premix Ex Taq (Takara, China). Tubulin gene (Gen Bank accession no TAU76544) was amplified similarly with primer pair P-qT (5'-TCGATGATCTCCAACTCCACCAGT-3' and 5'TCGTCGAACTCAGCACCAACTTCT-3') as the internal reference. The qRT-PCR was performed using TB Green ${ }^{\circ}$ Premix Ex Taq ${ }^{\text {Tw }}$ (Takara, China). It was performed in a total volume of $10 \mu \mathrm{L}$ containing $5 \mu \mathrm{L}$ of TB Green Premix Ex Taq, $2 \mu \mathrm{L}$ of cDNA and 2 pmol of each gene-specific primer. The reaction program was as follows: denaturation at $95^{\circ} \mathrm{C}$ for $3 \mathrm{~min}$, followed by 45 cycles at $95^{\circ} \mathrm{C}$ for $10 \mathrm{~s}$ and $60^{\circ} \mathrm{C}$ for $30 \mathrm{~s}$. All qRT-PCR assays were performed in three independent replications and the relative transcript level of each TaERF8 gene was determined using the $2^{-\triangle \Delta \mathrm{CT}}$ method [56].

\section{Molecular marker development}

Nucleotides of coding and flanking regions in TaERF8-2A, TaERF8-2B and TaERF8-2D were screened among different wheat accessions (Additional file 2: Table S1). Sequences alignment was conducted using SeqMan (DNASTAR Lasergene 7.1.0). Molecular markers were then designed accordingly based on polymorphic sites detected in TaERF8-2A and TaERF8-2B genomic sequences. Molecular marker TaERF8-2A-SNP (5'-CGCAGCCATTTGGAAACTAT-3' and 5'-AAGGTGCCGAGCCATACA-3') was designed based on a SNP detected in the intron of the TaERF8-2A. Molecular marker TaERF8-2B-InDel (5'-CCTTGTTAGA CTCCAAAATGCT-3' and 5'-CGAGCTCTTCTGAA CGCTT-3') was designed according to the InDel site found upstream of the TaERF8-2B start codon. The PCR amplification procedure was as follows: denaturation at $94{ }^{\circ} \mathrm{C}$ for 2 min, followed by 33 cycles of denaturation at $98^{\circ} \mathrm{C}$ for $10 \mathrm{~s}$, annealing at $56^{\circ} \mathrm{C}$ for $30 \mathrm{~s}$, and extension at $68^{\circ} \mathrm{C}$ for $15 \mathrm{~s}$, with a final extension at $68^{\circ} \mathrm{C}$ for $10 \mathrm{~min}$. Both pairs of molecular markers were used for genetic mapping of the corresponding gene, and the marker TaERF8-2B-InDel was further applied for TaERF8-2B haplotypes analysis.

\section{Isolation and bioinformatic analysis of protein sequences} The protein sequences of cloned ERFs in wheat and other species including Arabidopsis and rice were downloaded from the National Center for Biotechnology Information database (NCBI, http://www.ncbi.nlm.nih.gov) according to their accession number. Multiple sequence alignments of the ERFs were conducted using Clustal X [57] with default parameters and then viewed by the Jalview2 [58]. Phylogenetic analysis was performed with the protein sequences of TaERF8s and the other annotated ERFs from wheat, Arabidopsis, maize, rice and some other plant species by a Neighbor-Joining method with set parameters (poisson model, uniform rates and complete deletion) using MEGA 6.0 [59]. The robustness of the phylogenetic construction was tested by bootstrap method with 1000 replications.

\section{Supplementary information}

Supplementary information accompanies this paper at https://doi.org/10. 1186/s12870-020-02473-6.

Additional file 1: Figure S1. Nucleotide sequences of TaERF8-2A, TaERF8-2B and TaERF8-2D.

Additional file 2: Table S1. Wheat accessions information for TaERF8s polymorphism analysis.

Additional file 3: Figure S2. Nucleotide sequences of TaERF8-2A, TaERF8-2B and TaERF8-2D haplotypes.

Additional file 4: Table S2. The information of sample set 1 and their genotypes of TaERF8-2B.

Additional file 5: Table S3. Association analysis of TaERF8-2B haplotypes and agronomic traits in nine environments.

Additional file 6: Table S4. Summary of agronomical traits of sample set 1 in nine environments.

Additional file 7: Table S5. The information of sample set 2 and their genotypes of TaERF8-2B.

Additional file 8: Table S6. The frequencies of TaERF8-2B allelic variation in sample set 3 .

Additional file 9: Figure S3. The expression levels of $T a E R F 8-2 B$ in overexpression transgenic wheat lines and wild-type plants.

\section{Abbreviations}

AP2/ERF: APETALA2/Ethylene Responsive Factor; ERF: Ethylene Responsive Factor; TKW: 1000 kernel weight; QTL: Quantitative trait loci; SNP: Single nucleotide polymorphism; InDel: Insertion and Deletion; RIL: Recombinant inbred line; DH: Doubled haploid 


\section{Acknowledgments}

The authors would like to thank Dr. Ruilian Jing (Institute of Crop Science, CAAS) for kindly providing the $\mathrm{DH}$ population derived from $\mathrm{H} 10 / \mathrm{L} 14$ crossing for linkage mapping.

\section{Authors' contributions}

Experiments design: LG, GZ, PL and JJ; Performed the experiments: LZ; Data analysis: LZ, LG, LQ and JW1; Manuscript writing: LZ; Manuscript revision: LZ LG and JW2. The authors read and approved the final manuscript.

\section{Funding}

This work was supported by the National Key Research and Development Program (Project No. 2016YFD0100102) of China. The experimental design, data analysis and interpretation, and writing the manuscript were managed by the contributing authors.

\section{Availability of data and materials}

All data generated or analyzed during this study are included in this published article [and its additional files].

\section{Ethics approval and consent to participate}

Not applicable.

\section{Consent for publication}

Not applicable.

\section{Competing interests}

The authors declare that they have no competing interests.

Received: 26 August 2019 Accepted: 27 May 2020

Published online: 08 June 2020

\section{References}

1. Lata C, Mishra AK, Muthamilarasan M, Bonthala VS, Khan Y, Prasad M. Genome-wide investigation and expression profiling of AP2/ERF transcription factor superfamily in foxtail millet (Setaria italica L.). PLoS One. 2014;9:e113092. https://doi.org/10.1371/journal.pone.0113092.

2. Dey $\mathrm{S}$, Corina VA. Ethylene responsive factors in the orchestration of stress responses in monocotyledonous plants. Front Plant Sci. 2015;6:640. https:// doi.org/10.3389/fpls.2015.00640.

3. Nakano T, Suzuki K, Fujimura T, Shinshi H. Genome-wide analysis of the ERF gene family in Arabidopsis and rice. Plant Physiol. 2006;140:411-32. https:// doi.org/10.1104/pp.105.073783.

4. Licausi F, Ohme-Takagi M, Perata P. APETALA2/ethylene responsive factor (AP2/ERF) transcription factors: mediators of stress responses and developmental programs. New Phytol. 2013;199:639-49. https://doi.org/10. 1111/nph.12291.

5. Xu ZS, Chen M, Li LC, Ma YZ. Functions of the ERF transcription factor family in plants. Botany. 2008;86:969-77. https://doi.org/10.1139/B08-041

6. Xu ZS, Chen M, Li LC, Ma YZ. Functions and application of the AP2/ERF transcription factor family in crop improvement. J Integr Plant Biol. 2011;53: 570-85. https://doi.org/10.1111/j.1744-7909.2011.01062.x.

7. Zhang Z, Li F, Li D, Zhang H, Huang R. Expression of ethylene response factor JERF1 in rice improves tolerance to drought. Planta. 2010;232:765-74. https://doi.org/10.1007/s00425-010-1208-8.

8. Zhang HW, Liu W, Wan LY, Li F, Dai LY, Li DJ, et al. Functional analyses of ethylene response factor JERF3 with the aim of improving tolerance to drought and osmotic stress in transgenic rice. Transgenic Res. 2010;19:80918. https://doi.org/10.1007/s11248-009-9357-X.

9. Guo ZI, Chen XJ, Wu XL, Ling JQ, Xu P. Overexpression of the AP2/EREBP transcription factor OPBP1 enhances disease resistance and salt tolerance in tobacco. Plant Mol Biol. 2004;55:607-18. https:/doi.org/10.1007/s11103-004-1521-3.

10. Fischer U, Droge-Laser W. 2004. Overexpression of NtERF5, a new member of the tobacco ethylene response transcription factor family enhances resistance to tobacco mosaic virus. Mol Plant Microbe Interact. 2004:17: 1162-71. https://doi.org/10.1094/MPMI.2004.17.10.1162.

11. Fukao T, Bailey-Serres J. Submergence tolerance conferred by SubiA is mediated by SLR1 and SLRL1 restriction of gibberellin responses in rice. Proc Natl Acad Sci U S A. 2008;105:16814-9. https://doi.org/10.1073/pnas. 0807821105
12. Hattori Y, Nagai K, Furukawa S, Song XJ, Kawano R, Sakakibara H, et al. The ethylene response factors SNORKEL1 and SNORKEL2 allow rice to adapt to deep water. Nature. 2009;460:1026-30. https://doi.org/10.1038/nature08258.

13. Rong W, Qi L, Wang AY, Ye XG, Du LP, Liang HX, et al. The ERF transcription factor TaERF3 promotes tolerance to salt and drought stresses in wheat. Plant Biotechnol J. 2014;12:468-79. https://doi.org/10.1111/pbi.12153.

14. Zhu XL, Qi L, Liu X, Cai SB, Xu HJ, Huang RF, et al. The wheat ethylene response factor transcription factor pathogen-induced ERF1 mediates host responses to both the necrotrophic pathogen Rhizoctonia cerealis and freezing stresses. Plant Physiol. 2014;164:1499-514. https://doi.org/10.1104/ pp.113.229575.

15. Mehrnia M, Balazadeh S, Zanor MI, Mueller-Roeber B. EBE, an AP2/ERF transcription factor highly expressed in proliferating cells, affects shoot architecture in Arabidopsis. Plant Physiol. 2013;162:842-57. https://doi.org/ 10.1104/pp.113.214049

16. Ren DY, Li YF, Zhao FM, Sang XC, Shi JQ, Wang N, et al. MULTI-FLORET SPIKELET1, which encodes an AP2/ERF protein determines SPIKELET meristem fate and sterile lemma identity in rice. Plant Physiol. 2013;162: 872-84. https://doi.org/10.1104/pp.113.216044.

17. Qi WW, Sun F, Wang QJ, Chen ML, Huang YQ, Feng YQ, et al. Rice ethyleneresponse AP2/ERF factor OsEATB restricts internode elongation by downregulating a gibberellin biosynthetic gene. Plant Physiol. 2011;157:216-28. https://doi.org/10.1104/pp.111.179945.

18. Oh SJ, Kim YS, Kwon CW, Park HK, Jeong JS, Kim JK. Overexpression of the transcription factor AP37 in rice improves grain yield under drought conditions. Plant Physiol. 2009;150:1368-79. https://doi.org/10.1104/pp.109. 137554.

19. Sharman BC. Branched heads in wheat and wheat hybrids. Nature. 1944;153: 497-8. https://doi.org/10.1038/153497a0.

20. Xu ZS, Xia LQ, Chen M, Cheng XG, Zhang RY, Li LC, et al. Isolation and molecular characterization of the Triticum aestivum $L$. ethylene-responsive factor 1 (TaERF1) that increases multiple stress tolerance. Plant Mol Biol. 2007;65:719-32. https://doi.org/10.1007/s11103-007-9237-9.

21. Dong W, Ai XH, Xu F, Quan TY, Liu SW, Xia GM. Isolation and characterization of a bread wheat salinity responsive ERF transcription factor. Gene. 2012;511:38-45. https://doi.org/10.1016/j.gene.2012.09.039.

22. Dong N, Liu X, LU Y, Du LP, Xu HJ, Liu HX, et al. Overexpression of TAPIEP1 a pathogen-induced ERF gene of wheat confers host-enhanced resistance to fungal pathogen Bipolaris sorokiniana. Funct Integr Genomics. 2010;10:21526. https://doi.org/10.1007/s10142-009-0157-4.

23. Dobrovolskaya O, Pont C, Sibout R, Martinek P, Badaeva E, Murat F, et al. FRIZZY PANICLE drives supernumerary spikelets in bread wheat. Plant Physiol. 2015;167:189-99. https://doi.org/10.1104/pp.114.250043.

24. Poursarebani N, Seidensticker T, Koppolu R, Trautewig C, Gawroński P, Bini F, et al. The genetic basis of composite spike form in barley and 'miracle-wheat'. Genetics. 2015;201:155-65. https://doi.org/10.1534/genetics.115.176628.

25. Wu JX, Zhang ZG, Zhang Q, Liu YY, Zhu BT, Cao J, et al. Generation of wheat transcription factor FOX rice lines and systematic screening for salt and osmotic stress tolerance. PLoS One. 2015;10:e0132314. https://doi.org/ 10.1371/journal.pone.0132314.

26. Sakuma Y, Liu Q, Dubouzet JG, Abe H, Shinozaki K, Yamaguchi-Shinozaki K. DNA-binding specificity of the ERF/AP2 domain of Arabidopsis DREBs, transcription factors involved in dehydration- and cold-inducible gene expression. Biochem Bioph Res Co. 2002;290:998-1009. https://doi.org/10. 1006/bbrc.2001.6299.

27. Jing RL, Chang XP, Jia JZ, Hu RH. Establishing wheat doubled haploid population for genetic mapping by anther culture. Biotechnology. 1999; 9:4-8.

28. Lv C, Song YX, Gao LF, Yao Q, Zhou RH, Xu RG, et al. Integration of QTL detection and marker assisted selection for improving resistance to Fusarium head blight and important agronomic traits in wheat. Crop J. 2014;2:70-8. https://doi.org/10.1016/j.cj.2013.10.004.

29. Genc Y, Oldach K, Gogel B, Wallwork H, McDonald GK, Smith AB. Quantitative trait loci for agronomic andphysiological traits for a bread wheat population grown in environments with a range of salinity levels. Mol Breeding. 2013;32:39-59. https://doi.org/10.1007/s11032-0139851-y.

30. Genc $Y$, Oldach $K$, Verbyla AP, Lott G, Hassan M, Tester M, et al. Sodium exclusion QTL associated with improved seedling growth in bread wheat under salinity stress. Theor Appl Genet. 2010;121:877-94. https://doi.org/10. 1007/s00122-010-1357-y. 
31. Li QF, Zhang Y, Liu TT, Wang FF, Liu K, Chen JS, et al. Genetic analysis of kernel weight and kernel size in wheat (Triticum aestivum L.) using unconditional and conditional QTL mapping. Mol Breeding. 2015;35:194. https://doi.org/10.1007/s11032-015-0384-4

32. Fu YB, Somers DJ. Allelic changes in bread wheat cultivars were associated with long-term wheat trait improvements. Euphytica. 2011;179:209-25. https://doi.org/10.1007/s10681-010-0235-7.

33. Zhang HX, Zhang FN, Li GD, Zhang SN, Zhang ZG, Ma LJ. Genetic diversity and association mapping of agronomic yield traits in eighty six synthetic hexaploid wheat. Euphytica. 2017;213:111. https://doi.org/10.1007/s10681017-1887-3.

34. Thanh PT, Vladutu Cl, Kianian SF, Thanh PT, Ishii T, Nitta M, et al. Molecular genetic analysis of domestication traits in emmer wheat. I: map construction and QTL analysis using an F2 pupulation. Biotechnol Biotec Eq. 2013;27:3627-37. https://doi.org/10.5504/BBEQ.2013.0008.

35. Li T, Liu HW, Mai CY, Yu GJ, Li HL, Meng LZ, et al. Variation in allelic frequencies at loci associated with kernel weight and their effects on kernel weight-related traits in winter wheat. Crop J. 2019;7:30-7. https://doi.org/10. 1016/j.cj.2018.08.002

36. Bednarek J, Boulaflous A, Girousse C, Ravel C, Tassy C, Barret P, et al. Downregulation of the TaGW2 gene by RNA interference results in decreased grain size and weight in wheat. J Exp Bot. 2012;63:5945-55. https://doi.org/ $10.1093 / \mathrm{jxb} / \mathrm{ers} 249$.

37. Geng J, Li LQ, Lv Q, Zhao Y, Liu Y, Zhang L, et al. TaGW2-6A allelic variation contributes to grain size possibly by regulating the expression of cytokinins and starch-related genes in wheat. Planta. 2017;246:1153-63. https://doi.org/ 10.1007/s00425-017-2759-8.

38. Yan XF, Zhao L, Ren Y, Dong ZD, Cui DQ, Chen F. Genome-wide association study revealed that the TaGW8 gene was associated with kernel size in Chinese bread wheat. Sci Rep. 2019;9:1-10. https://doi.org/10.1038/s41598019-38570-2.

39. Wang YH, Li JY. Genes controlling plant architecture. Curr Opin Biotechnol. 2006;17:123-9. https://doi.org/10.1016/j.copbio.2006.02.004.

40. Börner A, Worland AJ, Plaschke J, Schumann E, Law CN. Pleiotropic effects of genes for reduced height $(R h t)$ and day-length insensitivity (Ppd) on yield and its components for wheat grown in middle Europe. Plant Breed. 1993; 111:204-16. https://doi.org/10.1111/j.1439-0523.1993.tb00631.x.

41. Peng JR, Richards DE, Hartley NM, Murphy GP, Devos KM, Flintham JE, et al. 'Green revolution' genes encode mutant gibberellin response modulators. Nature. 1999:400:256-61. https://doi.org/10.1038/22307.

42. Saville RJ, Gosman N, Burt CJ, Makepeace J, Steed A, Corbitt M, et al. The 'green revolution' dwarfing genes play a role in disease resistance in Triticum aestivum and Hordeum vulgare. J Exp Bot. 2012;63:1271-83. https:// doi.org/10.1093/jxb/err350.

43. Franckowiak JD, Lundqvist U. Descriptions of barley genetic stocks for 2012 . Barley Genet Newsl. 2012;42:792.

44. Chandler PM, Harding CA. Overgrowth' mutants in barley and wheat: new alleles and phenotypes of the 'green revolution' Della gene. J Exp Bot. 2013; 64:1603-13. https://doi.org/10.1093/jxb/ert022.

45. Wen W, Deng QY, Jia HY, Wei LZ, Wei JB, Wan HS, et al. Sequence variations of the partially dominant DELLA gene Rht-B1C in wheat and their functional impacts. J Exp Bot. 2013;64:3299-312. https://doi.org/10.1093/jxb/ert183.

46. Borner A, Plaschke J, Korzun V, Worland AJ. The relationships between the dwarfing genes of wheat and rye. Euphytica. 1996;89:69-75. https://doi.org/ 10.1007/BF00015721.

47. Kareiva P, Watts S, McDonald R, Boucher T. Domesticated nature: shaping landscapes and ecosystems for human welfare. Science. 2007;316:1866-9. https://doi.org/10.1126/science.1140170.

48. Luo MC, Yang ZL, You FM, Kawahara T, Waines JG, Dvorak J. The structure of wild and domesticated emmer wheat populations gene flow between them and the site of emmer domestication. Theor Appl Genet. 2007;114: 947-59. https://doi.org/10.1007/s00122-006-0474-0.

49. Guo ZA, Song YX, Zhou RH, Ren ZL, Jia JZ. Discovery, evaluation and distribution of haplotypes of the wheat Ppd-D1 gene. New Phytol. 2010;185: 841-51. https://doi.org/10.1111/j.1469-8137.2009.03099.x.

50. Li B, Li QR, Mao XG, Li A, Wang JY, Chang XP, et al. Two novel AP2/EREBP transcription factor genes TAPARG have pleiotropic functions on plant architecture and yield-related traits in common wheat. Front Plant Sci. 2016; 7:1191. https://doi.org/10.3389/fpls.2016.01191.

51. Zhang XK, Yang SJ, Zhou Y, He ZH, Xia XC. Distribution of the Rht-B1b, Rht$D 16$ and Rht8 reduced height genes in autumn-sown Chinese wheats detected by molecular markers. Euphytica. 2006;152:109-16. https://doi.org/ 10.1007/s10681-006-9184-6.

52. Ma DY, Yan J, He ZH, Wu L, Xia XC. Characterization of a cell wall invertase gene TaCwi-A1 on common wheat chromosome $2 \mathrm{~A}$ and development of functional markers. Mol Breeding. 2012;29:43-52. https://doi.org/10.1007/ s1 1032-010-9524-z.

53. Wei $B$, Jing RL, Wang $C S$, Chen JB, Mao XG, Chang XP, et al. Dreb1 genes in wheat (Triticum aestivum L.): development of functional markers and gene mapping based on SNPs. Mol Breeding. 2009;23:13-22. https://doi.org/10. 1007/s11032-008-9209-Z.

54. Yuan YY, Wang QZ, Cui F, Zhang JT, Du B, Wang HG. Specific loci in genome of wheat milestone parent Bima 4 and their transmission in derivatives. Acta Agron Sin. 2010;36:9-16. https://doi.org/10.1016/S18752780(09)60027-4.

55. Liu KJ, Muse SV. PowerMarker: an integrated analysis environment for genetic marker analysis. Bioinformatics. 2005;21:2128-9. https://doi.org/10. 1093/bioinformatics/bti282

56. Livak KJ, Schmittgen TD. Analysis of relative gene expression data using real-time quantitative PCR and the 2- ${ }^{\Delta \Delta C T}$ method. Methods. 2001;25:4028. https://doi.org/10.1006/meth.2001.1262.

57. Larkin MA, Blackshields G, Brown NP, Chenna R, McGettigan PA, McWilliam $\mathrm{H}$, et al. Clustal W and clustal X version 2.0. Bioinformatics. 2007:23:2947-8. https://doi.org/10.1093/bioinformatics/btm404.

58. Waterhouse AM, Procter JB, Martin DMA, Clamp M, Barton GJ. Jalview version 2-a multiple sequence alignment editor and analysis workbench. Bioinformatics. 2009;25:1189-91. https://doi.org/10.1093/bioinformatics/btp033.

59. Tamura K, Stecher G, Peterson D, Filipski A, Kumar S. MEGA6: molecular evolutionary genetics analysis version 6.0. Mol Biol Evol. 2013;30:2725-9. https://doi.org/10.1093/molbev/mst197.

\section{Publisher's Note}

Springer Nature remains neutral with regard to jurisdictional claims in published maps and institutional affiliations.

\section{Ready to submit your research? Choose BMC and benefit from:}

- fast, convenient online submission

- thorough peer review by experienced researchers in your field

- rapid publication on acceptance

- support for research data, including large and complex data types

- gold Open Access which fosters wider collaboration and increased citations

- maximum visibility for your research: over 100M website views per year

At BMC, research is always in progress.

Learn more biomedcentral.com/submissions 